\title{
The number of burr holes and use of a drain do not interfere with surgical results of chronic subdural hematomas
}

\author{
Tratamento cirúrgico do hematoma subdural crônico: o número de trepanações e o uso de \\ dreno subdural não interferem no resultado cirúrgico \\ Lindolfo Carlos Heringer ${ }^{1}$, Ulysses de Oliveira Sousa ${ }^{1}$, Matheus Fernandes de Oliveira ${ }^{1}$, Aline Silva Nunes ${ }^{1}$, \\ Katiusa de Abreu Alves', Maria Luiza Zancanaro', Ricardo Vieira Botelho'
}

\begin{abstract}
Burr hole evacuation has been the most frequently-used procedure for the treatment of chronic subdural hematomas (CSDH). Objective: To evaluate whether the use of a drain and/or the number of burr holes for treatment of CSDH modifies the rates of recurrence and complications. Methods: A retrospective review of 142 patients operated on because of CSDH, between 2006 and 2015 , analyzing recurrence and complications of the use of one or two burr holes with or without the use of a drain. Results: Thirty-seven patients had bilateral CSDH (26\%) and 105 (73.9\%) patients had unilateral CSDH. Twenty-two (59.4\%) patients were given a drain and 15 (40.6\%) were not. A total number of recurrences occurred in 22 (15.5\%) patients and the total number of complications was in six (4.2\%) patients. Mean follow-up time was 7.67 months. Conclusions: The number of burr holes and the use of the drain did not alter the rates of recurrence and complications in the treatment of CSDH.
\end{abstract}

Keywords: hematoma, subdural; recurrence; trephining.

\section{RESUMO}

A trepanação é o procedimento mais utilizado para o tratamento de hematomas subdurais crônicos (HSDC). Objetivo: Avaliar o uso de dreno subdural e / ou o número de trepanações para tratamento de HSDC modifica as taxas de recidiva e complicações. Métodos: Uma revisão retrospectiva de 142 pacientes operados por HSDC entre 2006 e 2015 analisando recidiva e complicações usando um ou dois orifícios com ou sem uso de dreno. Resultados: Trinta e sete casos apresentaram HSDC bilaterais (26\%) e 105 (73,9\%) unilaterais. Em vinte e dois $(59,4 \%)$ casos houve uso de dreno e em 15 (40,6\%) não houve. O número total de recidivas foi de 22 casos (15,5\%) e o número total de complicações foi de 6 casos (4,2\%). 0 tempo médio de seguimento foi de 7,67 meses. Conclusões: 0 número de trepanações e o uso do dreno não alteraram as taxas de recidiva e complicações no tratamento de HSDC.

Palavras-chave: hematoma subdural; recidiva; trepanação.

Chronic subdural hematoma (CSDH) is characterized by a chronic deposition of clot in the subdural space, usually with favorable prognosis ${ }^{1,2}$. It is a frequent neurosurgical condition, commonly associated with a previous history of trauma ${ }^{3}$. There is a variable incidence between 5.3 and 13.5 patients per 100,000 people per year, with a higher prevalence in the elderly ${ }^{4,5}$.

The main risk factors involved are advanced age, male gender, alcoholism and coagulopathies, including therapeutic anticoagulation and antiplatelet therapy ${ }^{1,2,6}$. Its treatment may be conservative or surgical, depending on symptoms and clot size ${ }^{3,7}$. Morbidity and mortality are low, however complications and recurrence are common ${ }^{7.8}$, especially when conditions such as older age, impairment of consciousness, midline shift, postoperative residual hematoma and comorbidities are present ${ }^{9}$.

In surgical cases, several techniques may be applied: one or two burr holes with or without the use of a drain; "twist drill craniostomy", craniotomy, and "endoscopic burr hole",3,10. Although there is no consensus on the best surgical technique to be employed ${ }^{7,11,12}$, burr hole evacuation of the hematoma has been the most frequently-used procedure and is considered the first option for treatment for $\mathrm{CSDH}^{11,12,1,1,14,15}$.

${ }^{1}$ Instituto de Assistência Médica ao Servidor Público Estadual, Programa de Pós Graduação, São Paulo SP, Brasil.

Correspondence: Matheus Fernandes de Oliveira; Rua Loefgreen, 700; 04040-000 São Paulo SP, Brasil; E-mail: mafernoliv@yahoo.com.br

Conflict of interest: There is no conflict of interest to declare.

Received 28 June 2017; Received in final form 03 August 2017; Accepted 07 August 2017. 
Burr holes, when associated with the use of a drain, have potentially better outcomes ${ }^{15,16}$. However, the literature is still divergent regarding the number of burr holes and the use of the drain ${ }^{17,18,19}$.

The present study aimed to evaluate whether the use of a drain and/or the number of burr holes for the treatment of a chronic subdural hematoma modifies the rates of recurrence and complications.

\section{METHODS}

A retrospective review of the patients operated on because of a CSDH in a single center (Hospital do Servidor Público Estadual de São Paulo) between 2006 and 2015 was carried out.

The project was approved by the Ethics and Research Committee.

\section{Sample}

One hundred fifty-five (155) surgeries in 155 patients were evaluated. Twelve patients were lost to follow-up and one patient had a craniotomy as the primary surgery. A total of 142 patients were finally evaluated. Follow-up time ranged from three to 21 months, with an average of 7.67 months.

Forty-two patients (29.5\%) were female and 100 (70.4\%) were male. Among the women, the mean age was $73 \pm 11.4$ years old. The mean age in the male group was $72.7 \pm 12.8$ years old. Twenty-two patients $(15.4 \%)$ were less than 60 years old; 45 patients $(31.7 \%)$ were $60-74$ years old and 75 patients $(52.8 \%)$ were 75 years or older $(73 \pm 12.4$ years old $)$.

\section{Primary outcomes}

The presence of recurrence and complications and the postoperative functional status (Glasgow Outcome Scale GOS) were evaluated in patients submitted to one or two burr holes and the use, or not, of a drain, and correlated with potential factors for recurrence, including: anthropometric data (age and gender), comorbidities, laterality of the hematoma (uni or bilateral), functional scales (American Society of Anesthesiologists (ASA) Score and GOS), one or two burr holes and the use, or not, of the drain.

Patients were divided by age into three groups: less than 60 years old, between 60 and 74 years old and those over 75 years old.

Comorbidities (surgical risk assessed by ASA), use of antiplatelet drugs or anticoagulants, alcoholism, and preoperative Glasgow Coma Scale (GCS) were recorded. The ASA surgical risk classification is a widely-used scale to classify surgical patients. A score of ASA 1 is a healthy patient with no organic changes; ASA 2 is a patient with mild or moderate systemic alteration; ASA 3 is a patient with severe systemic alteration with functional limitation; ASA 4 is a patient with severe systemic alteration representing life risk; and ASA 5 is a dying patient who is not expected to survive without surgery ${ }^{20}$.

\section{Surgical technique}

The burr holes created were either frontal or parietal or both, respectively at the Stephanion and Eurion craniometric points. In all procedures, additional irrigation with $0.9 \%$ saline was performed. The choice of the number of burr holes and the use, or not, of a drain was made by the surgeon, depending on the size and extent of the clot and the intraoperative findings.

\section{Statistics}

Data were described in absolute numbers and percentages. Numerical data were described by means and standard deviations. Evaluation of the association between recurrence and complications with or without the drain, number of burr holes, demographic and surgery data was performed using the $\mathrm{c}^{2}$ test, with Yates correction, when appropriate. The level of significance determined for the study was $\mathrm{p} \leq 0.05$. When the values for statistical analysis were zero, they were replaced by 0.5 for statistical calculation.

\section{RESULTS}

Among the men, 17 (17\%) presented with CSDH recurrence and six $(6 \%)$ presented with complications. Five women (11.9\%) presented with CSDH recurrence and none had complications. There was no significant difference between recurrence $\left(\chi^{2}=0.44, p=0.47\right)$ and complication rate $\left(\chi^{2}=0.20\right.$, $\mathrm{p}=0.79$ ) with respect to gender.

Among the patients under 60 years of age, four were reoperated on $(18.2 \%)$ and none had complications. In the 60 to 74 years age group, seven (15.5\%) presented with CSDH recurrence and one $(2.2 \%)$ presented with complications. There were 11 recurrences $(14.6 \%)$ and 5 (6.6\%) complications in the group of patients over 75 years old. There were no differences between the age group and reoperation rates $\left(\chi^{2}=0.92, p=0.31\right)$ and complications $\left(\chi^{2}=0.28, p=0.43\right)$.

Presenting symptoms were: motor deficit in 56 patients (39.4\%), headache in 13 patients (9.1\%), impaired consciousness in $12(8.4 \%)$, aphasia in $7(4.9 \%)$, seizure in $5(3.5 \%)$ and sensory deficit in $1(0.7 \%)$. The GCS score at the entrance to the emergency room ranged from 7 to 15, with a mean of 14 .

Seventeen patients reported a chronic use of alcohol. Of these, three presented with a recurrence of $\mathrm{CSDH}$ $(3 / 17)$ and one presented with $\mathrm{CSDH}$ complications (1/17). Twelve patients (8.4\%) were classified as ASA $1 ; 112$ $(78.8 \%)$ as ASA $2 ; 15(10.5 \%)$ as ASA $3 ; 3(2.1 \%)$ as ASA 4; and no patients as ASA 5.

Nineteen recurrences and four complications occurred in patients classified as ASA $\leq 2$, three recurrences and two complications in ASA $>2$. There was no difference among ASA 
groups and the number of reoperations $\left(\chi^{2}=0.88, \mathrm{p}=0.27\right)$ or complications $\left(\chi^{2}=0.12, p=0.72\right)$.

Thirty-seven patients had bilateral CSDH (26\%). There were $105(73.9 \%)$ patients with unilateral CSDH. Among the unilateral patients, 86 (81.9\%) were operated on with a single burr hole, and 19 (18\%) were operated on with two burr holes. Seventy-four (70.4\%) used a drain and 31 (29.5\%) did not (Table). Among patients with bilateral CSDH, 12 (32.4\%) patients were operated on with a single burr hole of each side and 25 (67.5\%) were operated on with two burr holes. Twenty-two (59.4\%) patients used drains and 15 (40.6\%) did not (Table).

At the end of the follow-up, three patients $(2.1 \%)$ were classified as GOS 3; 20 as GOS 4 (14.1\%); 119 as GOS 5(84\%) and no patients as GOS 1 or 2.

The total number of recurrences was $22(15.5 \%)$ and the total number of complications was 6 (4.2\%). Chi-square tests did not reveal statistically significant differences in recurrence rates according to the use, or not, of a subdural drain and the number of burr holes used in surgery (Table).

\section{DISCUSSION}

Chronic subdural hematoma is one of the most frequent diagnoses in neurosurgery ${ }^{1,2,3}$. It is characterized by an intracranial hemorrhage with a history of trauma in $50 \%$ of patients and occurs predominantly in males and in the elderly ${ }^{7,10,20,21}$.

Its incidence has increased considerably due to population aging $^{21}$, reaching 58 patients per 100,000 people in those aged 65 years old or more ${ }^{4}$. Most patients have complete remission of symptoms when diagnosed and treated early ${ }^{22,23,24}$.

Conditions such as the use of anticoagulants and antiplatelets, chronic alcohol use and the use of cerebrospinal fluid shunts (ventriculoperitoneal shunts) increase both the incidence and rates of complications and recurrences ${ }^{25,26,27}$, and may be important determinants of patient prognosis.

In this study, there was a higher prevalence of CSDH in males $(70.42 \%)$ and in those older than 60 years of age (84.5\%), with a mean age of 73 years. Epidemiological profiles were similar to those expected, with the exception of the mean age being greater than usually observed (63 years old $)^{2,7}$. Presenting symptoms were, respectively, motor deficit (39.4\%), headache (9.1\%) and impairment of consciousness/mental confusion (8.4\%), all in agreement with those described in the literature ${ }^{3,27}$.

Surgical treatment is the best therapeutic option for $\mathrm{CSDH}^{10}$. Several techniques are described in the literature (burr hole or craniotomy). There is still insufficient scientific evidence to justify the choice of the best technique $e^{20,21,22,23}$. Since it is a procedure with few operative risks and with good efficacy, a burr hole has been the preferred choice for most neurosurgeons ${ }^{25,26,27}$, and is the most-used technique.

A burr hole is associated with reoperation rates ranging from $9.25 \%$ to $26.5 \%^{16}$. There is disagreement concerning the number of burr holes and possible outcomes ${ }^{7}$. According to Taussky et al. ${ }^{19}$, rates of recurrence and complications were considerably lower in patients operated on with two burr holes $(\mathrm{p}<0.001)$. Nevertheless, most of the studies did not show significant differences between the use of one or two burr holes ${ }^{22,23,24}$.

The pathophysiology of $\mathrm{CSDH}$ consists of repeated microbleeding of bridging veins after traumatic injury, mainly in atrophic elderly brains. In the young, they are more frequently associated with higher energy trauma or coagulopathies. Initial bleeding leads to inflammation and subsequent formation of a capsule with vascular neoformation, which may then bleed, increasing the size of the hematoma. Surgery consists of opening the capsule and removing the clot. The use of a drain potentially removes residual bleeding after the burr hole and decreases the number of recurrences. The available data suggest better results with the use of the drain ${ }^{13,14,15,16,17}$. However, in our sample there was no difference with or without drain usage.

There was no association among any of the predictor factors studied and the presence of complications, which occurred in six out of 142 patients.

There were no statistically significant differences among the recurrence rate and any of the other predictors.

Some limitations should be described. Firstly, this was a retrospective study and thus some biases of data harvest and follow-up of patients may be missing or incomplete.

Secondly, outcomes of patients with CSDH are complex and also depend on several clinical and neurological features, not only the neurosurgical technique and strategies.

In conclusion, the number of burr holes and the use of a drain to treat CSDH did not alter the rates of recurrence and complications.

Table. Surgical data of unilateral and bilateral chronic subdural hematoma

\begin{tabular}{|c|c|c|c|c|c|c|c|c|c|c|c|c|}
\hline \multirow{3}{*}{ Variable } & \multicolumn{6}{|c|}{ Unilateral chronic subdural hematoma } & \multicolumn{6}{|c|}{ Bilateral chronic subdural hematoma } \\
\hline & \multicolumn{2}{|c|}{ Drain } & \multirow{2}{*}{$\mathrm{p}$} & \multicolumn{2}{|c|}{ Burrhole } & \multirow{2}{*}{$p$} & \multicolumn{2}{|c|}{ Drain } & \multirow{2}{*}{$\mathrm{p}$} & \multicolumn{2}{|c|}{ Burrhole } & \multirow{2}{*}{$p$} \\
\hline & With & Without & & One & Two & & With & Without & & One & Two & \\
\hline $\mathrm{n}$ & 74 & 31 & & 86 & 19 & & 22 & 15 & & 12 & 25 & \\
\hline Recurrence & $16.2 \%$ & $9.6 \%$ & 0.73 & $12.8 \%$ & $21.1 \%$ & 0.56 & $13.6 \%$ & $26.7 \%$ & 0.6 & $8.3 \%$ & $24 \%$ & 0.69 \\
\hline Complication & $2.7 \%$ & $6.4 \%$ & 0.55 & $23.2 \%$ & $10.5 \%$ & 0.52 & $9.1 \%$ & 0 & 0.42 & 0 & $8 \%$ & 0.48 \\
\hline
\end{tabular}


1. Poulsen FR, Halle B, Pottegård A, Rodríguez LAG, Hallas J, Gaist D. Subdural hematoma cases identified through a Danish patient register: diagnosis validity, clinical characteristics, and preadmission antithrombotic drug use. Pharmacoepidemiol Drug Saf. 2016;25(11):1253-62. https://doi.org/10.1002/pds.4058

2. Soleman J, Taussky P, Fandino J, Muroi C. Evidence-based treatment of chronic subdural hematoma. In: Sadaka F, Quinn T, editors. Traumatic brain injury. Rijeka: Intech; 2014 [cited 2016 Dec 10]. Available from: http://www.intechopen.com/books/traumatic-braininjury/evidence-based-treatment-of-chronic-subdural-hematoma

3. Castro-Rodríguez C, Román-Pena P, Arán-Echabe E, Gelabert-González M. [Chronic subdural haematomas in very elderly patients]. Rev Esp Geriatr Gerontol. 2016;51(6):309-16. Spanish. https://doi.org/10.1016/j.regg.2016.05.003

4. Andersen-Ranberg NC, Poulsen FR, Bergholt B, Hundsholt T, Fugleholm K. Bilateral chronic subdural hematoma: unilateral or bilateral drainage? J Neurosurg. 2017;126(6):1905-11. https://doi.org/10.3171/2016.4.JNS152642

5. Sharon LY, Wai Hoe NG. "Subarachnoid cyst" after evacuation of chronic subdural hematoma: case report of an unusual postoperative morbidity. Asian J Neurosurg. 2016;11(3):316. https://doi.org/10.4103/1793-5482.144210

6. Alves JL, Santiago JG, Costa G, Mota Pinto A. A standardized classification for subdural hematomas - I. Am J Forensic Med Pathol. 2016;37(3):174-8. https://doi.org/10.1097/PAF.0000000000000255

7. Abe Y, Maruyama K, Yokoya S, Noguchi A, Sato E, Nagane M et al. Outcomes of chronic subdural hematoma with preexisting comorbidities causing disturbed consciousness. J. Neurosurg. 2017;126(4):1042-6. https://doi.org/10.3171/2016.3.JNS152957

8. Kolias AG, Chari A, Santarius T, Hutchinson PJ. Chronic subdural haematoma: modern management and emerging therapies. Nat Rev Neurol. 2014;10(10):570-8. https://doi.org/10.1038/nrneurol.2014.163

9. Muzii VF, Bistazzoni S, Zalaffi A, Carangelo B, Mariottini A, Palma L. Chronic subdural hematoma: comparison of two surgical techniques. Preliminary results of a prospective randomized study. J Neurosurg Sci. 2005;49(2):41-6.

10. Ducruet AF, Grobelny BT, Zacharia BE, Hickman ZL, DeRosa PL, Andersen KN et al. The surgical management of chronic subdural hematoma. Neurosurg Rev. 2012;35(2):155-69. https://doi.org/10.1007/s10143-011-0349-y

11. Cenic A, Bhandari M, Reddy K. Management of chronic subdural hematoma: a national survey and literature review. Can J Neurol Sci. 2005;32(4):501-6. https://doi.org/10.1017/S0317167100004510

12. Ramachandran R, Hegde T. Chronic subdural hematomas: causes of morbidity and mortality. Surg Neurol. 2007;67(4):367-72. https://doi.org/10.1016/j.surneu.2006.07.022

13. Santarius T, Kirkpatrick PJ, Ganesan D, Chia HL, Jalloh I, Smielewski $P$ et al. Use of drains versus no drains after burr-hole evacuation of chronic subdural haematoma: a randomised controlled trial. Lancet. 2009;374(9695):1067-73. https://doi.org/10.1016/S0140-6736(09)61115-6
14. Erol FS, Topsakal C, Faik Ozveren M, Kaplan M, Tiftikci MT. Irrigation vs. closed drainage in the treatment of chronic subdural hematoma.J Clin Neurosci. 2005;12(3):261-3. https://doi.org/10.1016/j.jocn.2003.09.012

15. Liu W, Bakker NA, Groen RJ. Chronic subdural hematoma: a systematic review and meta-analysis of surgical procedures. J Neurosurg. 2014:121(3):665-73. https://doi.org/10.3171/2014.5.JNS132715

16. Han HJ, Park CW, Kim EY, Yoo CJ, Kim YB, Kim WK. One vs. two burr hole craniostomy in surgical treatment of chronic subdural hematoma. J Korean Neurosurg Soc. 2009;46(2):87-92. https://doi.org/10.3340/jkns.2009.46.2.87

17. Smith MD, Kishikova L, Norris JM. Surgical management of chronic subdural haematoma: one hole or two? Int J Surg. 2012;10(9):450-2. https://doi.org/10.1016/j.ijsu.2012.08.005

18. Rovlias A, Theodoropoulos S, Papoutsakis D. Chronic subdural hematoma: Surgical management and outcome in 986 cases: a classification and regression tree approach. Surg Neurol Int. 2015;6(1):127. https://doi.org/10.4103/2152-7806.161788

19. Taussky P, Fandino J, Landolt H. Number of burr holes as independent predictor of postoperative recurrence in chronic subdural haematoma. Br J Neurosurg. 2008;22(2):279-82. https://doi.org/10.1080/02688690701818885

20. Lee JK, Choi JH, Kim CH, Lee HK, Moon JG. Chronic subdural hematomas : a comparative study of three types of operative procedures.J Korean Neurosurg Soc. 2009;46(3):210-4. https://doi.org/10.3340/jkns.2009.46.3.210

21. Kansal R, Nadkarni T, Goel A. Single versus double burr hole drainage of chronic subdural hematomas: a study of 267 cases. J Clin Neurosci. 2010;17(4):428-9. https://doi.org/10.1016/j.jocn.2009.07.109

22. Xu C, Chen S, Yuan L, Jing Y. Burr-hole Irrigation with Closed-system Drainage for the Treatment of Chronic Subdural Hematoma: A Meta-analysis. Neurol Med Chir (Tokyo). 2016;56(2):62-8. https://doi.org/10.2176/nmc.ra.2015-0013

23. Kutty SA, Johny M. Chronic subdural hematoma: a comparison of recurrence rates following burr-hole craniostomy with and without drains. Turk Neurosurg. 2014;24(4):494-7. https://doi.org/10.5137/1019-5149.JTN.8830-13.1

24. Zumofen D, Regli L, Levivier M, Krayenbühl N. Chronic subdural hematomas treated by burr hole trepanation and a subperiostal drainage system. Neurosurgery. 2009;64(6):1116-21. https://doi.org/10.1227/01.NEU.0000345633.45961.BB

25. Javadi SA, Naderi F, Javadi AM. The optimal surgical approach for treatment of chronic subdural hematoma: questionnaire assessment of practice in Iran and review of literature. Acta Med Iran. 2015;53(10):617-21.

26. Gelabert-Gonzalez M, Lopez-García E, Fernandez-Villa JM. Chronic subdural hematoma treated by burr holes and closed drainage system: a review of 630 cases. Med Princip Pract. 2001;10(2):41-7. https://doi.org/10.1159/000050338

27. Song DH, Kim YS, Chun HJ, Yi HJ, Bak KH, Ko Y et al. The predicting factors for recurrence of chronic subdural hematoma treated with burr hole and drainage. Korean J Neurotrauma. 2014;10(2):41-8. https://doi.org/10.13004/kjnt.2014.10.2.41 